\title{
Shaping the future: Recent advances of 3D printing in drug delivery and healthcare
}

Sarah J Trenfield ${ }^{\text {1a }}$, Atheer Awad ${ }^{\text {1a }}$, Christine Madla ${ }^{1}$, Grace Hatton ${ }^{1}$, Jack Firth ${ }^{1}$, Alvaro Goyanes $^{2,3}$, Simon Gaisford ${ }^{1,2}$ and Abdul W Basit ${ }^{1,2 *}$

a) Both authors contributed equally to this work

${ }^{1}$ UCL School of Pharmacy, University College London, 29-39 Brunswick Square, London WC1N 1AX, UK

${ }^{2}$ FabRx Ltd., 3 Romney Road, Ashford, Kent, TN24 ORW, UK

${ }^{3}$ Departamento de Farmacología, Farmacia y Tecnología Farmacéutica, R + D Pharma Group (GI-1645), Universidade de Santiago de Compostela, 15782, Spain.

*Correspondence: a.basit@ucl.ac.uk (Abdul W. Basit)

Key words: Three-dimensional printing; Oral drug delivery systems; Digital healthcare; Additive manufacturing; 3D printed drug products; Personalized drug products 


\section{Abstract \\ Introduction}

Three-dimensional (3D) printing is a relatively new, rapid manufacturing technology that has found promising applications in the drug delivery and medical sectors. Arguably, never before has the healthcare industry experienced such a transformative technology. This review aims to discuss the state of the art of 3D printing technology in healthcare and drug delivery.

\section{Areas Covered}

The current and future applications of printing technologies within drug delivery and medicine have been discussed. The latest innovations in 3D printing of customised medical devices, drug-eluting implants and printlets (3D printed tablets) with a tailored dose, shape, size and release characteristics have been covered. The review also covers the state of the art of 3D printing in healthcare (covering topics such as dentistry, surgical and bioprinting of patient-specific organs), as well as the potential of recent innovations, such as 4D printing, to shape the future of drug delivery and to improve treatment pathways for patients.

\section{Expert Opinion}

A future perspective is provided on the potential for 3D printing in healthcare, covering strategies to overcome the major barriers to integration that are faced today. 


\section{Introduction}

The healthcare industry is changing rapidly, with the traditional 'one-size-fits-all' treatment approaches becoming a thing of the past. According to an National Health Service (NHS) England report, this conventional treatment pathway involving mass manufacture of medicines is ineffective in up to $70 \%$ of patients, creating an urgent need for new therapies to be personalised to the individual [1]. Traditional manufacturing processes are wholly unsuitable for the production of personalised drug delivery therapies, involving inherently labour-intensive, dose-inflexible and time-consuming processes. This creates a need for the healthcare industry to adapt and embrace new platforms for tailored therapy production.

Three-dimensional (3D) printing, an additive manufacturing technique, is set to become a major disruptive technology in healthcare by enabling the production of bespoke objects of virtually any shape and size, layer by layer [2]. Structures can be created from a digital 3D file using computer-aided design (CAD) software or imaging techniques, such as magnetic resonance imaging (MRI) or computed tomography (CT) scans, to readily manufacture objects that are individualised to each patient [3]. 3D printing processes differ from each other in the nature of the material used (e.g. plastics, ceramics, metals, resins), technology of deposition, mechanism of formation of the layers or the characteristics of the obtained product (e.g. final shape, surface finish, texture, geometrical shape, mechanical properties). The American Society for Testing and Materials (ASTM) classifies these technologies into seven categories of machines based on the additive process involved; namely material extrusion, material jetting, powder bed fusion, binder 
jetting, vat photopolymerisation, sheet lamination and directed energy deposition (Table $1)$. 


\begin{tabular}{|c|c|c|c|}
\hline ASTM Category & Technologies & Substrate & Mechanism of Layering \\
\hline Binder jetting & $\begin{array}{l}\text { Powder bed inkjet printing } \\
\text { S-printing } \\
\text { M-printing } \\
\text { Theriform }^{\text {TM }} \\
\text { ZipDose }^{\circledR}\end{array}$ & $\begin{array}{l}\text { Solid particles (plastic, } \\
\text { metal, sand, polymer) }\end{array}$ & $\begin{array}{l}\text { A liquid binding agent is } \\
\text { selectively deposited to join } \\
\text { powder materials }\end{array}$ \\
\hline Vat polymerisation & $\begin{array}{l}\text { Stereolithography (SLA) } \\
\text { Digital light projection (DLP):SEp } \\
\text { Continuous layer interface } \\
\text { production (CLIP) }\end{array}$ & Liquid (photopolymer) & $\begin{array}{l}\text { Liquid photopolymer in a vat } \\
\text { is selectively cured by light- } \\
\text { activated polymerisation }\end{array}$ \\
\hline Powder bed fusion & $\begin{array}{l}\text { Selective laser sintering (SLS)isEp: } \\
\text { Direct metal laser sintering (DLSM) } \\
\text { Selective metal sintering (SLM) } \\
\text { Electron beam melting } \\
\text { (EBM) }\end{array}$ & $\begin{array}{l}\text { Solid particles (metal, } \\
\text { plastic, polymer) }\end{array}$ & $\begin{array}{l}\text { Thermal energy selectively } \\
\text { fuses regions of a powder } \\
\text { bed }\end{array}$ \\
\hline Material extrusion & $\begin{array}{l}\text { Fused deposition modelling (FDM) } \\
\text { Gel/paste extrusion }\end{array}$ & $\begin{array}{l}\text { Filament (thermoplastic } \\
\text { polymers e.g. ABS; PLA; } \\
\text { PC; ULTEM } \\
\text { TM resin) }\end{array}$ & $\begin{array}{l}\text { Material is selectively } \\
\text { dispensed through a nozzle } \\
\text { or an orifice }\end{array}$ \\
\hline Material jetting & $\begin{array}{l}\text { Ink-jet printing } \\
\text { Polyjet } \\
\text { Thermojet }\end{array}$ & $\begin{array}{l}\text { Liquid (acrylic-based } \\
\text { photopolymers, elastomeric } \\
\text { photopolymers, wax-like } \\
\text { materials) }\end{array}$ & $\begin{array}{l}\text { Droplets of built material are } \\
\text { selectively deposited }\end{array}$ \\
\hline $\begin{array}{l}\text { Directed energy } \\
\text { deposition }\end{array}$ & $\begin{array}{l}\text { Electron beam direct Manufacturing } \\
\text { Direct metal tooling (DMT) } \\
\text { Be additive manufacturing (BeAM) }\end{array}$ & Wire (metal) & $\begin{array}{l}\text { Focused thermal energy is } \\
\text { used to fuse materials by } \\
\text { melting as they are being } \\
\text { deposited }\end{array}$ \\
\hline
\end{tabular}


Since the introduction of $3 \mathrm{D}$ printing nearly three decades ago, this technology has transformed manufacturing in a boundless field of applications. To this day, 3D printing is often employed to create engineering prototypes due to its fast production speed and costeffectiveness and was in fact first invented for this purpose [4]. Indeed, it seems that the applications of 3D printing are limited only by the imagination, with reports of car parts, customised fashion accessories, organs and even houses being produced using this technology $[5,6]$. The applications of 3D printing do not stop there. Indeed, 3D printing is set to become a revolutionary technology within healthcare; due to its capability to produce bespoke and individualised objects, personalised medical prosthetics, implants and devices that can be tailored to the individual needs of each patient [7]. In the field of drug delivery, various constructs have already been prepared using 3D printing ranging from drug-eluting implants, medical devices and personalised solid oral dosage forms [8-14].

As such, this technology has been explored as a viable method of personalising medicines at the point of use and with a view to expand into rapid throughput screening of new drug candidates on 3D printed biological tissue to identify intra-individual therapeutic responses [15]. 3D printing is competitive for small-scale production of medical devices and drug products that require customisation and frequent dosage modification, and for products that require complex geometries. Such customisation is not attainable using conventional mass manufacturing processes, and has shown a benefit in patient compliance and achieving tailored drug release profiles $[16,17]$. This review will provide a comprehensive overview on the most recent advances of 3D printing in healthcare, covering the current and future applications in drug delivery and medicine, as well as new innovations and concepts such as the impact of $4 \mathrm{D}$ printing on drug delivery. 


\section{Applications of 3D Printing}

In medicine, 3D printing offers an advantage limited by other approaches: personalized drug delivery systems, prosthetic devices (such implantable defibrillators and equipment) and even tissues and organs can be made-to-measure and made-to-order for a specific purpose, be that man or machine. The added benefits - cost-effectiveness; simplified production techniques; and increased opportunities for collaboration - are equally attractive. The current healthcare uses for 3D printing can be characterised into five main categories (Figure 1); dentistry, tissue and organ fabrication; anatomical 3D models used for surgical training; pharmaceuticals and creating patient specific medical devices (such as prosthetics and implants). This section will discuss these existing and future medical applications of 3D printing in turn, and its potential to revolutionise manufacturing for this purpose. Examples of the different medical applications of 3D printing can be found in table 2 . 


\section{D Printing}

Medical

Applications

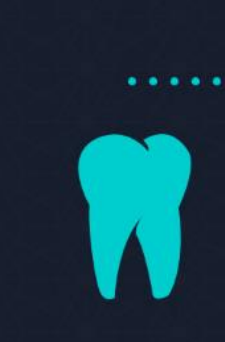

Dentistry

Anatomical Models

Pharmaceuticals

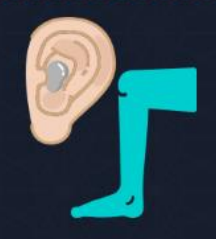

Medical Devices

Surgical tools Implants Prostheses

Orthoses Hearing aids

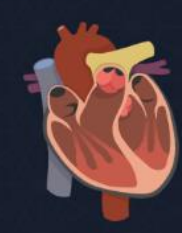

Tissues and Organ

Tissue analogues (for implantation) Disease models Organ-on-a-chip

Surgical guides medical training and education) Orally disintegrating formulations

used:
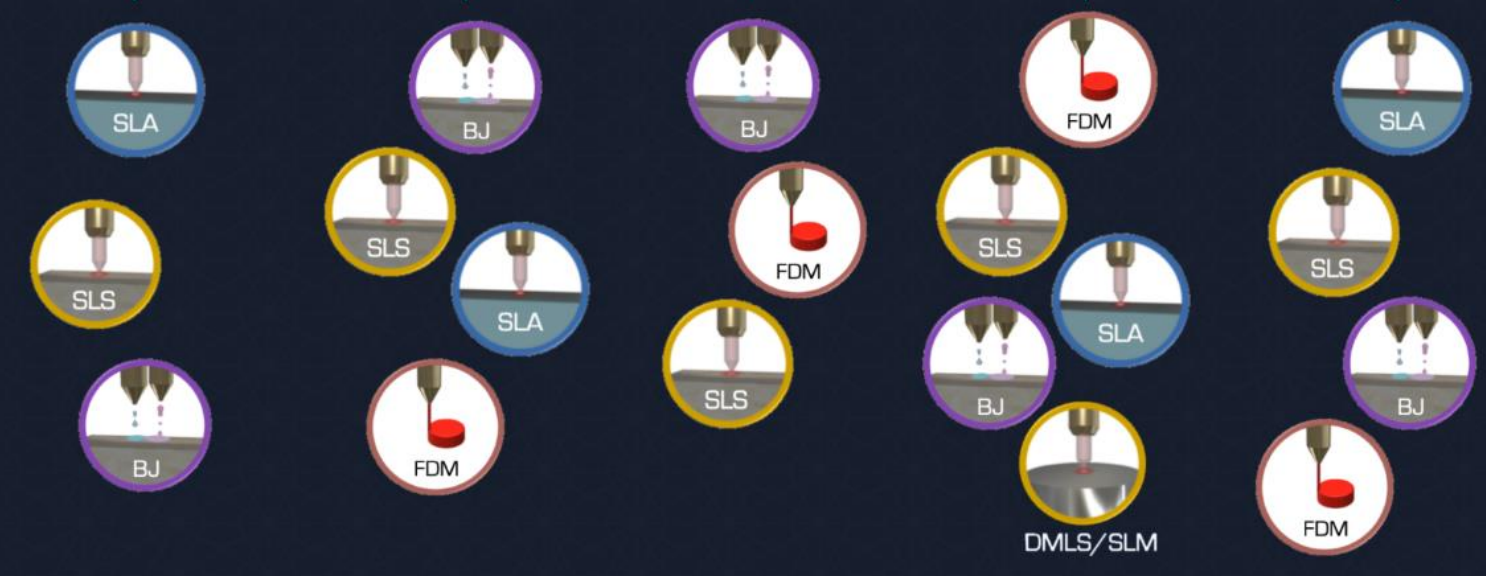

Figure 1. Current medical and healthcare applications of 3D printing. SLA = stereolithography, SLS = selective laser sintering, FDM = fused deposition modelling, DMLS = direct metal laser sintering, SLM = selective laser melting, $\mathrm{BJ}=$ binder jetting. 
Table 2. Examples of the medical applications of 3D printing. FDM = fused deposition modelling, SLA = stereolithography, , DLP = direct light processing, SLS = selective laser sintering, BJ = binder jetting, PLA = polylactic acid, ABS = acrylonitrile butadiene styrene, $\mathrm{PEGDA}=$ polyethylene (glycol) diacrylate, PLGA $=$ poly(lactic-co-glycolic acid), PCL = polycaprolactone, $\mathrm{TPU}=$ thermoplastic polyurethane, $\mathrm{HPMC}=$ hydroxypropyl methylcellulose.

\begin{tabular}{|c|c|c|c|}
\hline Application & 3D printing technology & Main Polymer composition & References \\
\hline Scaffold for tissue regeneration & FDM & PLA, ABS & [18] \\
\hline Osteochondral scaffolds & SLA & PEGDA, PLGA & {$[19,20]$} \\
\hline In vivo bone regeneration & DLP & Vinyl ester, Vinyl carbonate & {$[21]$} \\
\hline Biodegradable scaffolds & Inkjet & PLGA, Collagen & {$[22,23]$} \\
\hline Scaffolds for tissue regeneration & SLS & PCL, Gelatine & {$[24,25]$} \\
\hline Implants & FDM & TPU & [26] \\
\hline Drug delivery systems & FDM & PCL & {$[27]$} \\
\hline Drug-loaded systems & Inkjet & HPMC & {$[28]$} \\
\hline $3 \mathrm{D}$ printed pellets for dual-drug therapy & SLS & Ethyl cellulose, Kollicoat IR & [29] \\
\hline 6-layer polypill for multi-drug therapy & SLA & PEGDA & {$[30]$} \\
\hline Surgical guides and aids & FDM & ABS & {$[31]$} \\
\hline Pre-surgical planning & Polyjet & Photosensitive resin & {$[32]$} \\
\hline Dental models & DLP & Photosensitive resin & [33] \\
\hline
\end{tabular}


Pre-surgical planning

Diagnosis and treatment planning
BJ

Polyjet
TPU

Acrylic resin

\subsection{Dentistry}

To date, 3D printing has been extensively adopted in the field of dentistry for a number of applications, ranging from creation of orthodontic surgical models to production of replacement teeth $[36,37]$. As such, 3D printing has been forecast to become a $\$ 3.1$ billion industry in this sector by 2020 [38]. The most widely referred to example of 3D printing in dentistry is for the product Invisalign ${ }^{\circledR}$, which are 3D printed transparent orthodontic devices that straighten teeth without the use of traditional metal braces [5].

With the advances of small scanning systems, in the future, instead of patients having moulds to be sent to a specialised lab for scanning and retainer production (a process that can take weeks), instead a small intraoral camera could be used to scan a patient's misshapen teeth [39]. The digitised scan could then be sent to a local 3D printer for retainer production, creating a 'digital dentistry' service. 3D printer manufacturers have identified the growing need for 3D printers qualified for the production of dentistry parts and hence recent developments have been undertaken. As an example, Stratasys have recently introduced two specifically designed semi-solid extrusion printers for the purposes of dentistry known as CrownWorx ${ }^{\mathrm{TM}}$ and FrameWorx ${ }^{\mathrm{TM}}[40]$. The printers extrude a form of wax designed to allow dental laboratories to create tailor-made crowns and bridges. Researchers have also shown the potential of light-curing 3D printing technologies to 
produce patient-specific dentures with unique antibacterial properties via the inclusion of $\mathrm{TiO}_{2}$ within a polymeric resin (polymethyl methacrylate; PMMA) [41].

Furthermore, recent studies have highlighted the potential for 3D bioprinting to produce patient-specific composite tissues for tooth tissue engineering. In particular, the researchers developed a fibrin-based bio-ink for printing within human dental pulp stem cells, and printing via micro-patterns enabled over $88 \%$ viability of stem cells [42].

\subsection{Anatomical 3D Models}

There lie multitudinous opportunities for 3D printing applications in surgery ranging from the modelling of tumours and other abnormal tissue structures in vitro to inform surgical approaches and medical, as well as patient, education [43]. Before the introduction of 3D printing, in vitro models were poorly representative of tumour structural complexity and crude approximations of tumour microenvironments. More recently, 3D models have been used to enable more detailed reconstruction of tumour features from cellular proliferation and migration to blood vessel organisation and metastases [44,45]. Rapid prototying of such constructions has been widely studied in the cardiovascular, radiology and surgical oncology fields, as well as to observe fracture fixations in bone, in turn enabling a better planning and preparation of surgical staff before procedures are conducted [46,47]. This also feeds in to the use of 3D printing in transplantation. One case study demonstrated the use of CT scanning in imaging a paediatric patient's airway to subsequently generate a 3D printed tracheal splint [48]. Indeed, this is a useful area of 3D printing in both modelling 
and in practical utilisation of models to support surgical intervention namely in the generation of splints and guiding templates for resection of bone and other materials, as well as suturing devices [49].

In the same vein, the use of 3D printing has extended to the development of targeted tumour therapies, such as in chemotherapy-impregnated mesh devices that can be modelled to specifically fit a given tumour that may otherwise be surgically unachievable and which previously may have spelt the death knell for affected patients. This has already been prototyped in animal models for pancreatic cancer [50] whereby a patient-customised 3D printed bioabsorbable implant is targeted to the tumour site and releases drug at constant therapeutic levels over a period of 4 weeks. [51].

\subsection{D Printing of Oral Drug Products}

To date, 3D printing has been used to create a range of complex formulations that would not easily be produced by conventional manufacturing technologies. This technology provides a high flexibility enabling the production of a multitude of drug products with tailored release profiles and designs, ranging from controlled-release formulations, fastdissolving tablets and multi-drug combinations [11,52-54]. Drug release can be controlled by varying three main parameters; namely the printlet geometry, infill percentage and polymer inclusion. 
Table 3. Latest innovations in dosage form geometry using 3D printing. Reprinted with permission from $[16,29,30,55]$.

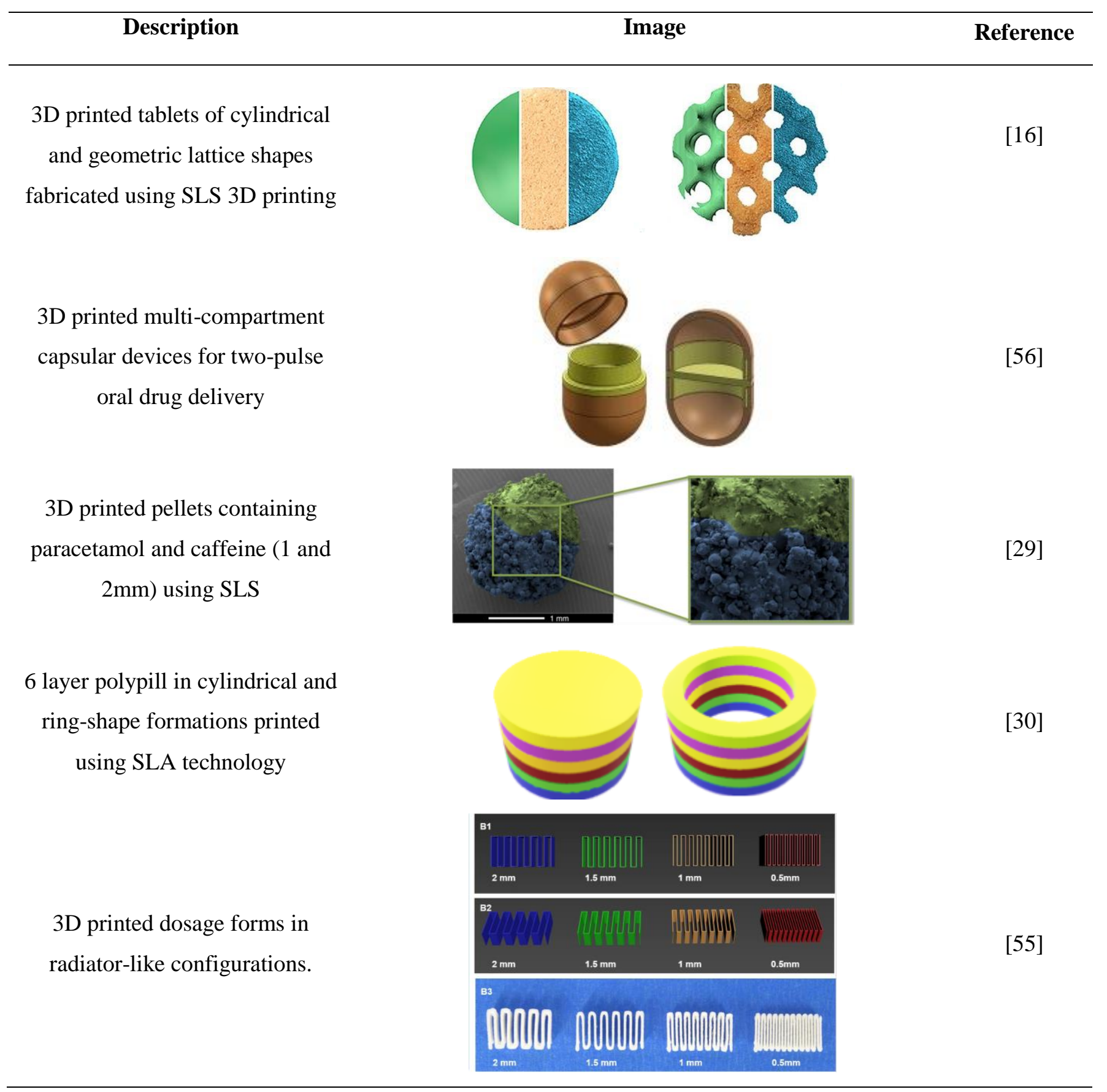

As an example, several studies have highlighted the ability for drug release to be tailored 
based on printlet design $[57,58]$. In one study, printlets were fabricated using SLS with cylindrical and gyroid lattice structures and demonstrated the ability to achieve customisable release characteristics based on the geometry selected, with lattice structures demonstrating faster drug release compared with the cylindrical tablet [16] (Table 3).

Theophylline-loaded printlets with innovative 'radiator-like designs' have also recently been developed using FDM printing [55]. Each dosage form had connected paralleled plates with inter-plate spacing of either $0.5,1,1.5$ or $2 \mathrm{~mm}$. The researchers found that the minimal spacing between parallel plates of the design should be $1 \mathrm{~mm}$ to enable an immediate drug release from the structures.

Infill percentage (that is the degree to which the internal space will be filled from $0 \%$, hollow, to $100 \%$, solid), has also been found to be another determinant influencing the drug release [59]. Previous studies have shown that printlets with a lower infill percentage exhibit a faster drug release, whereas tablets with higher infill percentages showed extended release profiles [60]. On the contrary, in a study carried out by Chai et al., a change in infill percentage was exploited to create gastroretentive tablets [61]. This was mainly due to the difference in densities, wherein, tablets having $0-20 \%$ infill had a density that was lower than that of the fluid media, causing them to float. The buoyancy effect increased the residence time of the tablets in the gastric region, promoting drug absorption from the early part of the small intestine. However, such phenomenon is highly dependent upon a patient's diet and thus, a high variability in performance is expected.

Advantageously, certain 3D printing processes (such as SLS and binder jetting [62]) have 
been found to be capable of formulating highly porous and fast-dissolving tablets [63]. This is due to the process loosely binding powder particles together and hence relying solely on this weak force to maintain object integrity (instead of mechanical compression force). As such, rapidly dispersible tablets can be formulated due to the ease of water penetration throughout the formulation matrix. For example, Fina et al. showed, for the first time, the application and capability for SLS to produce orodispersible printlets, simply by changing the laser speed at which the powder particles were sintered [64]. This dosage form demonstrated acceptable pharmacotechnical properties and average disintegration times were rapid ( $<4$ seconds). Previous studies have also highlighted the potential for binder jet printing to create rapidly-dispersing orodispersible tablets [65]. Indeed, the first commercially available application of 3D printing medicines is utilising this unique benefit that powder bed printing processes have. By virtue of its binder jet printing manufacturing process which forms highly porous tablets, Spritam ${ }^{\circledR}$ is capable of rapidly dissolving in the mouth with an average disintegration time of $11 \mathrm{~s}$ (ranging from 2 to $27 \mathrm{~s}$ ), providing the intake of a small sip of liquid, even with a high drug load of levetiracetam (up to $1 \mathrm{~g}$ dose per tablet) [66].

3D printing has also been shown advantageous in creating amorphous solid dispersions of drugs within dosage forms, particularly favourable for enhancing drug release of poorly soluble compounds (such as BCS Class II or IV drugs) [10,67,68]. To date, the majority of these studies have 3D printed using polymeric materials for stabilisation of drug within the matrices. As an example, one study showed the potential for a novel 3D printing technology, termed direct powder extrusion, to produce itraconazole-loaded printlets as amorphous solid dispersions directly from powdered materials, obviating the need for a the 
often lengthy development times for filament production required in FDM technology [69]. Recent research has also highlighted the capability for 3D printing to create lipid-based formulations, (in particular, solid self-microemulsifying drug delivery systems; SSMEDDS) to improve drug release of poorly water-soluble drugs [70,71].

Due to the capabilities for precise and flexible spatial distribution of material, 3D printing has been widely researched in the production of multi-drug combinations (or polypills). Thus far, a number of papers have demonstrated the production of polypills using a range of printing technologies [72-74]. For example, Pereira et al. successfully printed a fourdrug cardiovascular polypill [75]. Further to this, 3D printed polypills containing six different drugs (paracetamol, naproxen, caffeine, prednisolone, aspirin and chloramphenicol) have been printed in multilayer cylindrical and ring-shaped formations designed to improve medication adherence for patients on polypharmacy treatment regimes [30]. In recent research, Awad et al. demonstrated the ability to produce 3D printed pellets (miniprintlets) containing a single drug (paracetamol) and two spatially separated drugs (paracetamol and ibuprofen) in $1 \mathrm{~mm}$ and $2 \mathrm{~mm}$ diameters (Table 2) [29]. By varying the polymer, the dual miniprintlets were programmed to achieve customised drug release patterns, whereby one drug was released immediately from a Kollicoat IR matrix, whilst the effect of the second drug was sustained over an extended time span using ethyl cellulose.

The invention of 3D printed polypills containing spatially-separated compartments is of high value, permitting the use of drugs incompatible with one another. In late 2017, a dual compartmental oral device was devised for the treatment of tuberculosis containing two 
drugs which are inherently incompatible (isoniazid and rifampicin) [12]. Separate formulations containing isoniazid and rifampicin were inserted into separate compartments, preventing the release of the drugs together within the gastric region. Thus, it was evident that such approach is beneficial for reducing the interaction caused by this combination therapy. Furthermore, the concept of dual compartments can also be utilised to target different regions of the gastrointestinal tract.

The benefits of 3D printing could also have a wide-reaching impact on global health, tackling major challenges such as counterfeiting of medicines. It is estimated $10.5 \%$ of low- and middle-income countries are imposed by substandard or falsified medicines, costing an estimated US\$ 30.5 billion annually. To overcome this, one study developed a unique track-and-trace and anti-counterfeit method, whereby QR codes and smart material inks were printed directly on the surface of paracetamol-loaded tablets to ensure product authenticity [76].

\subsection{Innovative Medical Devices}

3D printing can also be used to produce bespoke medical devices. To date, designing and printing personalised implants and prostheses has become the gold-standard method and solution for many patients who require specific constructs. In particular, 3D printing has been widely used to fabricate dental parts [77], trauma medical implants and orthopaedic medical devices (e.g. knee and hip joint devices) [78]. Unlike other production methods, $3 \mathrm{D}$ printing offers an easy manufacturing method that is less expensive, where the end products are tailored specifically for the patient.

3D printing has also been used to prepare drug-containing nose masks specifically tailored 
to the patient for the treatment of acne [79]. In the study, a 3D scanner was utilised to scan the patient's nose and the 3D design was generated which could create a mask that was personalised to the patient. This was followed by a similar work conducted by Muwaffak et al., where they 3D printed anatomically tailored wound dressings containing zinc, silver and copper as their anti-microbial agents in the shape of a nose and an ear [8]. The adaptation of masks specific to patients helped in holding the dressings in the wound position, gaining further advantage over their analogous flat dressings.

In other studies, 3D printing has been utilised to create personalised 3D printed intrauterine and subcutaneous devices [80,81]. In both studies, results have shown that the drug release was faster in the $3 \mathrm{D}$ printed devices compared to that from the extruded filaments. This was attributed to the presence of the drug in the amorphous form in the $3 \mathrm{D}$ printed structures, whereas the drug particles in the filaments were in the crystalline form. A similar work conducted by Tappa et al. has shown that hormone-eluting intra-uterine devices, meshes and rods fabricated using 3D printing could provide an extended activity over a period of one week [27]. Furthermore, due to the capability for a precise control over material deposition, 3D printing has been used to create patient-specific implants $[51,82]$. Such intricate structures have been found to encourage bone growth and provide localised drug therapy, thereby securing the implant firmly in place upon healing. Other similar examples include the customisation of 3D printed stents [26], airway splints [83], hearing aids [84] surgical meshes containing contrast agents [85] and wearable sensors [86]. Such advances of 3D printing can enable better outcomes for patients post-operatively and accelerate healing.

Due to the strict regulations on patients' health and safety, only a few 3D printed products 
are currently commercially available, mainly including anatomical surgical guides and artificial prosthesis. However, following the approval of Spritam ${ }^{\circledR}$, the regulatory bodies have shown an increased interest in 3D printing. Recently, the FDA has set up an Emerging Technology Team (ETT) consisting of a group of pharmaceutical experts to support and promote the regulatory evaluation of emerging manufacturing technologies, including 3D printing [87]. This was followed by the issuance of a guidance for the 'Technical Considerations for Additive Manufactured Devices" [88]. Thus, more 3D printed drug products and medical devices are anticipated to hit the market sooner than expected.

\subsection{Bioprinting Tissues and Organs}

There is an increasing demand for the bioprinting of tissues and organs. It is estimated that around twenty patients in the U.S.A alone die each day whilst awaiting organ transplantation [89], and though still premature as an option for addressing global organ donor shortages, 3D printing offers a potential solution nonetheless [90]. Advances in 3D printing technology have broached the realm of regenerative medicine, ensuring that the printing of biological materials is now very much reality over fantasy. Indeed, such bioprinters are capable of printing not only stem cells but of building organs and blood vessels in a cell-by-cell fashion, enabling printing of tissues fit for human use on demand using automated, laser-calibrated print heads (Figure 2) [91]. Such capacity would not only arguably remove the need for cadaveric or live-donor transplants (often at risk of rejection owing to tissue or cellular incompatibly with the recipient host alongside prolonged waiting lists for human "matches") but would also potentially allow for elective transplantation of 
organs in areas such as ageing and regenerative medicine which are both relatively new fields of investigation for pre-emptive treatment per se [92].

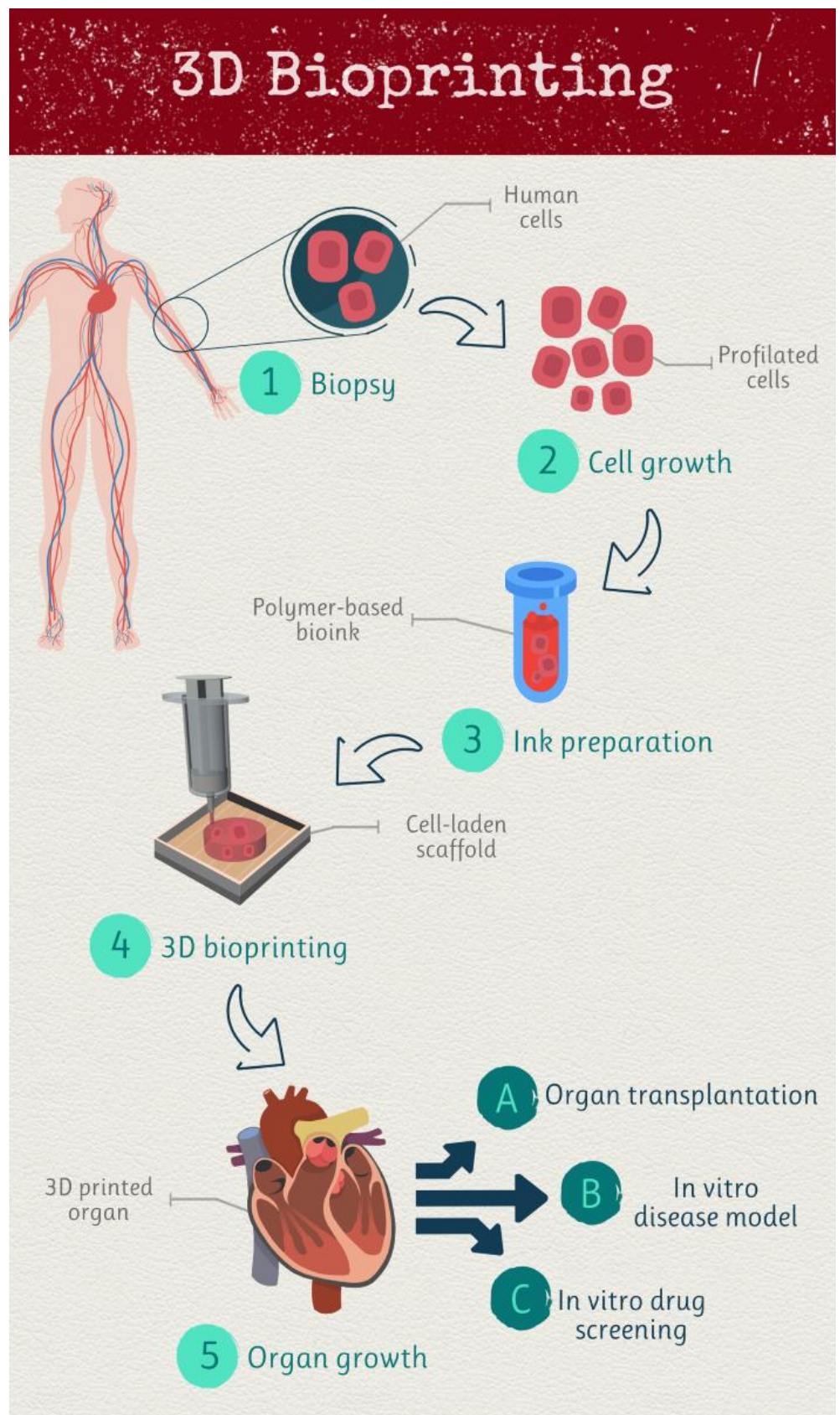

Figure 2. Pathway for bioprinting of patient-specific tissues and organs for applications in transplantation, disease models and drug screening. 
The U.S.A. stem cell research company Celprogen Inc. ${ }^{\circledR}$ is one such pioneer of $3 \mathrm{D}$ organ bioprinting having successfully engineered one of the world's first 3D printed human heart that is currently being validated for human use [93]. This was made from polylactic acid (PLA) material that was populated with adult human cardiac stem cells. In December 2016, Celprogen Inc. ${ }^{\circledR}$ also announced the successful 3D printing of a human pancreas from PLA seeded with adult human pancreatic stem cells. The organ was coated with extracellular matrix protein and seeded with pancreatic stem cells from two different human lines which then successfully differentiated into a functional adult pancreas [94]. Similar to the work

of Celprogen Inc. ${ }^{\circledR}$, ETH Zurich have manufactured a silicone heart that is capable of beating like the real organ using a lost-wax casting 3D printing technique [95]. Much work, however, is required to optimise the silicone 3D printed heart as its current iteration only lasts for 3000 beats, sufficient to keep someone alive for 30-45 min. Having said this, this work has highlighted the potential for 3D printing to provide a promising solution to the lack of organ donations.

\section{4D Printing}

Driven by the disruptive stream of innovative opportunities, the novel concept of fourdimensional (4D) printing emerged. Built on the conceptual underpinnings of 3D printing, the 4D printing method integrates a fourth-dimension; namely time. The printed products have the capability to change their configuration (e.g. change in shape, property, or functionality) over time. This often occurs in response to an external stimulus, such as heat, 
light, $\mathrm{pH}$, magnetic or electric forces or moisture. Examples of transformative actions include self-assembly, self-dissembling, self-repair or change in colour. Transformation into this 'fourth dimension' is a result of the feedstock itself (using smart materials) and a predetermined 3D design in which the product is created (known as smart design) (Figure $3)$.

\section{D Vs. 4D Printing}

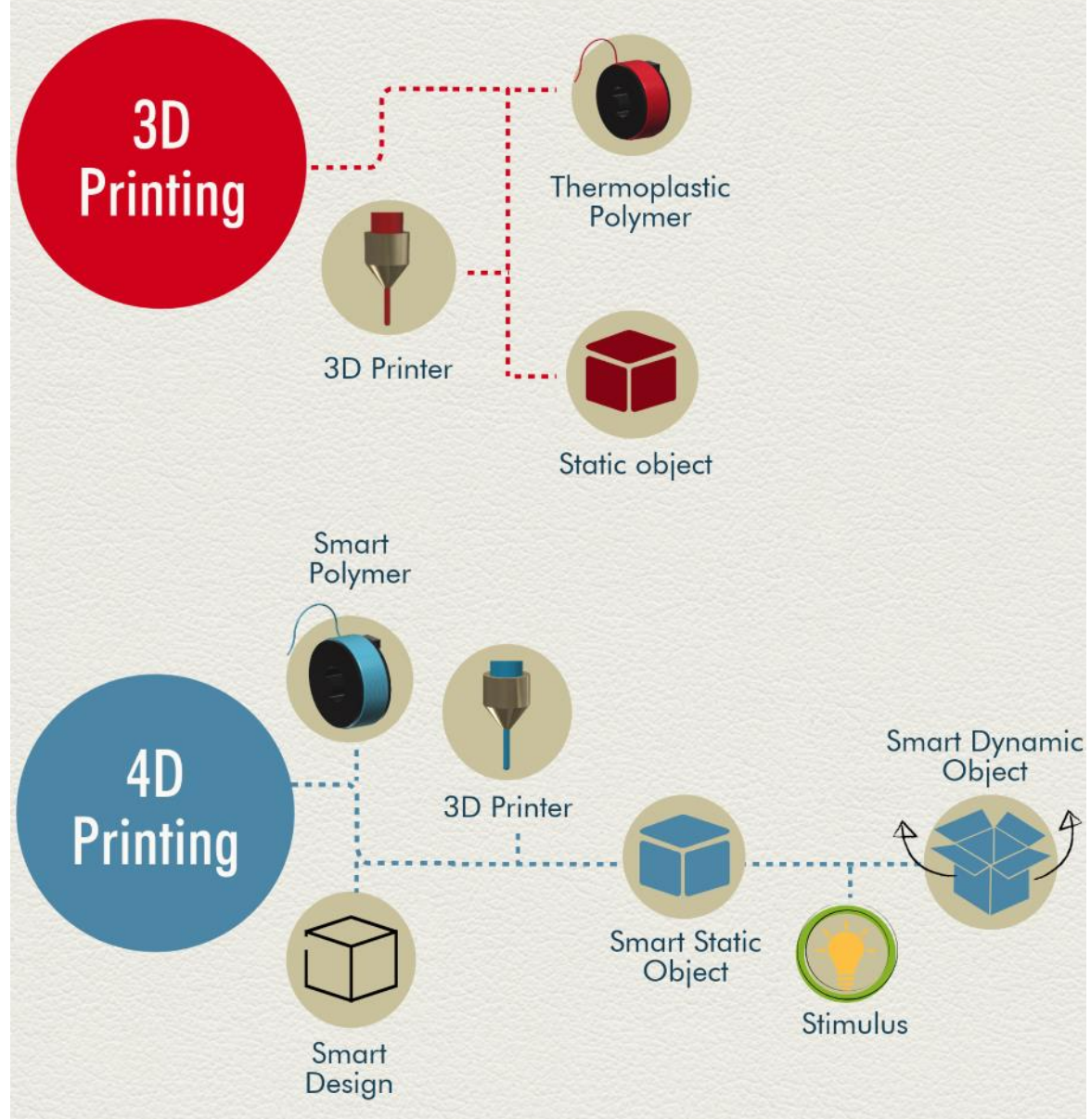

Figure 3. Schematic illustration outlining the differences between 3D printing and 4D printing. 
Smart materials, also known as intelligent or responsive materials, are those that have reactive responses, whereby they exhibit a predetermined when exposed to a certain stimulus. There are two main types of smart material that have been used in 4D printing thus far; (a) hydrogels, which swell when exposed to specific solvents, such as water and (b) shape memory polymers (SMPs), which respond to different stimuli, such as temperature, $\mathrm{pH}$ or $\mathrm{UV}$ radiation. In the case of hydrogels, water diffuses into the polymer matrix of the fabricated structures inducing swelling and resulting in the change of their morphology. Researchers at MIT exploited this concept by printing hinges composed of hydrogels to connect rigid hydrophobic structures. Upon exposure to water, the hinges swell and bend, producing a 3D cube structure [49]. On the other hand, SMPs are polymers that adopt a temporary configuration until exposed to a certain external stimulus, causing them recover to their permanent morphology. More specifically, when the smart material is introduced to the stimulus, it reaches a critical inflection point, known as its glass transition temperature $(\mathrm{Tg})$. At the rested state, the temperature of the polymer is below its $\mathrm{Tg}$, meaning it is in its brittle, glassy state. As the temperature elevates above the $\mathrm{Tg}$, the polymer transitions into a viscous, more flexible form, known as its rubbery state. This makes the material soft and pliable, enabling specific and predetermined changes in its structural morphology. Once the temperature falls below the $\mathrm{Tg}$ again, the material transitions back to its permanent or rested state. Due to their intricate structures, it is often difficult and time-consuming to produce stents using conventional manufacturing approaches. Favourably, owing to their transformative properties, SMPs have been widely applied for the fabrication of dynamic stents that are able to contort when exposed to the 
body temperature after insertion into a patient [96]. As such, using 4D printing, stents of any size and shape can be produced in a time and cost-efficient manner. Interestingly, the use of multiple smart approaches could provide synergistic effects. An example of such are 3D printed stents composed of iron oxide, a material that responds to magnets, combined with a PLA-based ink having thermo-responsive properties. Unlike conventional stents, these smart structures have the combined benefits of being personalised for each individual patient while having the ability to be controlled remotely [97,98].

In addition to being composed of smart materials, the programming of $4 \mathrm{D}$ printed objects is dependent upon the 3D design of the object. More specifically, to induce predetermined morphological changes, the structure and the orientation of the smart materials within the object should be considered carefully [96]. In simpler terms, 4D printing essentially is based on the 3D printing of smart materials to create dynamic structures with the ability to self-fold or unfold. It is important to note that many of these smart materials have already previously been applied to pharmaceutics and drug delivery. Although they were not used for 3D printing, it is still possible to predict their likely applications within 4D printing. Based upon their drug delivery mechanisms, we can classify objects made using smart materials into two categories; bio-adhesive and encapsulation devices.

Bio-adhesive devices are drug delivery systems that induce drug release by affixing to the intestinal endothelium. An example of such includes a tri-layered, muco-adhesive device composed of an outer $\mathrm{pH}$ sensitive hydrogel. Once in the small intestine $(\mathrm{pH}=6.5)$, the device contorts and grips onto the intestinal wall. The gripping mechanism increases the intestinal residence time of the devices, allowing more drug to diffuse into mucosal epithelium [99]. A similar approach includes the 'theragrippers', which are thermo- 
responsive eluting devices, characterised for having multiple arms [100]. These devices are programmed to spontaneously grip and affix onto tissue once subjected to temperatures above $32^{\circ} \mathrm{C}$. Advantageously, due to their high porosity, the structures could be loaded with high amounts of drug, which in turn provides a constant drug release up to 7 days. Building upon this concept, the incorporation of iron oxide nanoparticles into the porous hydrogel layer provides an added magnetic responsive feature, via which the devices could be remotely transported to their target site within a clinical setting or during surgery or even used as surgical tools themselves [101].

Encapsulation devices on the other hand, are self-assembling structures that fold into closed containers in which different materials, such as fibroblasts, pancreatic beta cells and yeast cells [102], could be contained [103]. Unlike conventional dosage forms, these smart devices are programmed to release their contents when exposed to predetermined temperatures [104]. An example of this system includes bilayer micro-robots, consisting of a pH-responsive layer and an iron oxide-based layer, which were fabricated by conventional lithography for anticancer therapy [105]. The dual mechanism consists of the use of a magnetic force to remotely guide the micro-robots to the tumour site, after which they are activated by the acidic nature of the tumour tissue $(\mathrm{pH}=4.5-6.0)$, causing them to release their contents and provide targeted therapy, reducing the cell viability by $70 \%$ whilst limiting the amount of drug that passes throughout the systemic circulation.

Due to its novelty, 4D printing as a concept has minimally applied to pharmaceutical formulation. Recently, Melocchi et al. have explored this concept to fabricate retentive 
devices for the intravesical delivery of medicines [106]. They utilised SMPs that were programmed to hold a temporary conformation allowing administration into the bladder. Once in contact with water, the devices transform back into their permanent shapes, permitting them to be retained in the bladder (Figure 4). The increase in the intravesical residence time could enhance the efficiency of treatment by providing prolonged, localised drug delivery. Although still primitive, the use of $4 \mathrm{D}$ printing within pharmaceutics could reinvigorate the concepts of drug delivery, making it possible to create medications that were previously challenging to produce.

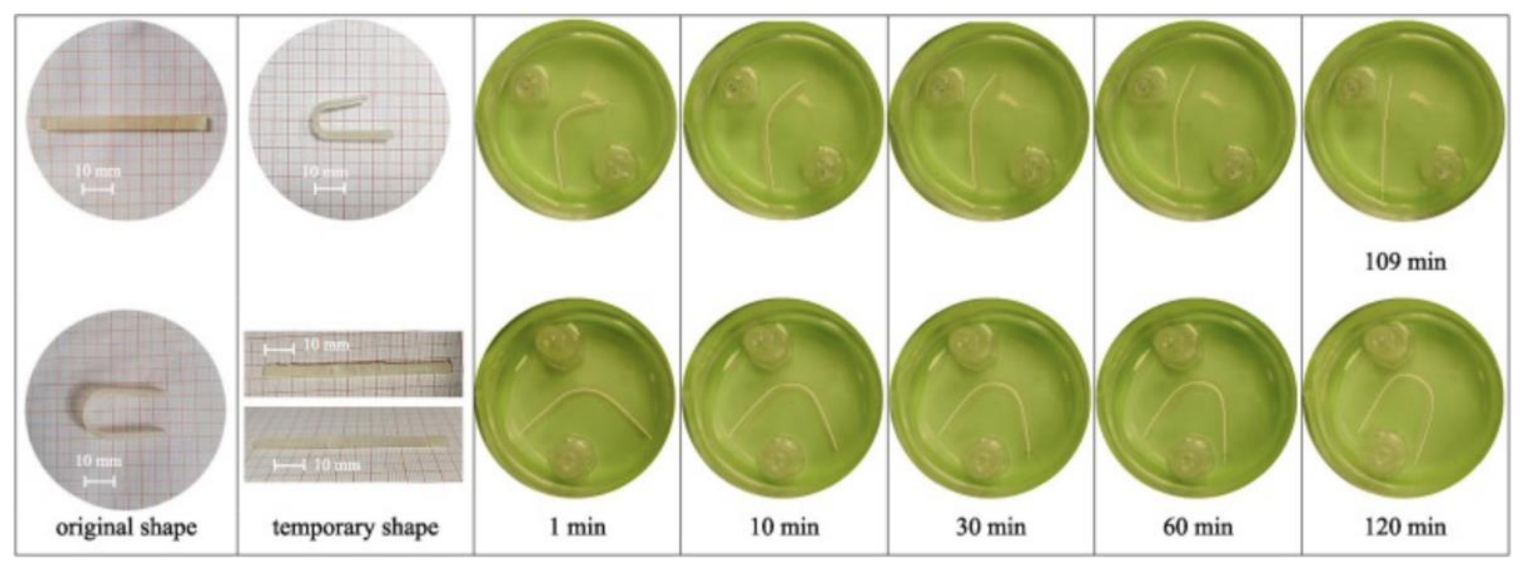

Figure 4. Images outlining the shape memory properties (at room temperature) of the intravesical devices having an original I- and U-shape fabricated by FDM 3D printing. A solid line is superimposed to highlight the recovery process. (Reprinted with permission from [106])

\section{Benefits and Challenges of 3D Printing in Drug Delivery and Medicine}

The benefits of 3D printing also range far beyond its ability to be personalised. Financially, 3D printing offers a competitive alternative to smaller-scale production costs; one example being NASA who utilised 3D printing to produce a rocket fuel injector at a third of the cost previously via traditional manufacturing approaches. Other areas of cost-effectiveness 
extend to areas such as the pharmaceutical industry whereby customisation of specific drugs may enable dose and cost reduction depending on intra-individual profiling for therapeutic dosing and equally in the rapid rate of production of on-demand objects and devices versus multiple-process manufacture in industry or otherwise. This has been exemplified in the generation of 3D printed in vitro models considered easier to image, manipulate and process at a higher throughput compared to in vivo models. Another important benefit of 3D printing and specifically in medicine as well as other fields, is in collaboration and data sharing - a pioneer of this being the National Institutes of Health $(\mathrm{NIH})$, who founded the shared 3D printing data network 3D Print Exchange. Initially used in-house where 3D printers are available throughout the institute's campus for data sharing of software and images for 3D printing, this is now an open-access resource enabling all users to share 3D print files for various devices.

Although 3D printing offers promising applications and capabilities within the field of medicine, an important obstacle to consider is the feasibility of use in a clinical setting. As with the advent of any other avant-garde technology, and as is especially the case in medicine, regulatory requirements and limitations also apply to the constantly-evolving field of 3D printing, rendering the development of new applications within both an ethically and safety-specific grey area. Whilst printing speeds, processing speeds and resolutions have significantly advanced over the past few years with respect to 3D printing, these parameters have lagged behind the optimal levels often employed for scale-up manufacturing techniques. However, more recently, the FDA have developed a draft guidance to promote the technical considerations specific to devices using additive manufacturing which is promising for the scope of 3D manufacturing [107]. 
The potential for $3 \mathrm{D}$ printing as a solution to personalisation as well as on-demand generation of surgical and medical equipment is an exciting and very real one, aside from its other potential in the personalisation and on-demand printing of medicines and medical devices for individual patient use be that via handheld 3D printing devices, use of in situ printing approaches with precise dimensional specifications, or large-scale 3D printing manufacture. Others have postulated that harnessing stem cells at birth or in early life could even allow for bioprinting of regenerative tissues via the medium of 3D printing.

\section{Conclusion}

Though 3D printing is still in its infancy within the pharmaceutical sector, the transition to 4D might occur beforehand. The use of 'smart drugs' can provide a more targeted therapy that can be personalised for the necessities of each individual patient, initiating a digital revolution within drug delivery and healthcare. Whether this is ultimately adopted as such an approach remains to be seen, though the ever-growing research and non-expert utilisation of such drug delivery systems would suggest in favour. Nonetheless, as the FDA supports the development of complex dosage forms and the use of innovative manufacturing approaches using science and risk-based approaches, this may accelerate the adoption of such innovative technologies within healthcare. Currently, technical and quality control limitations are the dominant constraints that hinder the adoption of 3D printing. It is anticipated that once an ideal printing platform is established, it will be a matter of time before 3D printers takeover pharmaceutical shelves, commencing a new era of digital health. 


\section{Expert Opinion}

Whilst technological improvements are constantly being made insofar as this notion is concerned, preliminary results appear promising. In particular, it is foreseen that $3 \mathrm{D}$ printing is well suited to be used within digital health domains, changing the face of pharmaceutical manufacture. A favourable aspect would include its adoption by the pharmaceutical industry as a feasible alternative to current fabrication methods. However, many would argue that this technology is still primitive and its goal is not to replace mass production but to complement it for instance, in the production of complex dosage regimes of drugs with narrow therapeutic indices, where accurate dosing is needed to maintain treatment efficacy and patient safety, or biological products, which are often unstable under storage conditions. Alternatively, 3D printing could be leveraged for the production of ondemand dosage forms tailored to the needs of challenging patient subgroups, such as young children and the elderly, where dosing requirements can be markedly different when compared with adults.

By integrating a $4^{\text {th }}$ dimension such as time, it possible to achieve dynamic structures with programmable shapes, properties, or functionality. The use of novel strategies such as 4D printing is advantageous within the pharmaceutical sector, especially for the advancement of controlled drug delivery. By evaluating smart materials currently applied in pharmaceutical formulation, the initial applications and beneficial attributes of 4D printing can be unveiled. For instance, by applying 4D printing to produce structures of high resolution and complexity, not only would the process improve in terms of time and cost efficiency, but also the opportunity for bespoke treatments emerges. Within pharmaceutics, the most valuable purpose of this process is the fabrication of engineered drug delivery 
devices for targeted therapies. This could be achieved by utilising $\mathrm{pH}$ as a stimulus, permitting the affixation of formulations to specific regions in the gastrointestinal tract. In turn, the use of such smart systems provides superior drug absorption within the site of action, improving the efficacy of treatment.

It is clear that the integration of 3D printing into clinical practice could pave the way for a digital health revolution, changing the way medicines are designed and prescribed for patients. However, the healthcare sector is known for being notoriously resilient to change, owing to the presence of regulatory guidelines and clinical standards, both of which pose technical and quality control challenges. Though such regulations promote patient safety, they are often a stumbling block in the route of modern technological advancements. Indeed, as the evidence-base for 3D printing continues to grow, it is becoming evident that action is required to translate the theoretical benefits of 3D printing into real-world benefits for patients.

To date, a limited number of in vivo studies have been carried out albeit with highly promising results. In 2017, the first in vivo acceptability study was performed using whereby 3D printed dosage forms were designed to have a variety of different shapes and sizes, which were evaluated for ease of swallowing and handling in human volunteers [17]. Novel diamond shape structures were designed to be structurally raised enabling an ease of handling in patients with dexterity challenges. In terms of swallowing, patients were found to prefer the torus, cylinder and oblong shapes, demonstrating how different 3D printing geometries could be used to improve medication acceptability. Following on from this work, Liang. et al. undertook a first-in-human study of a 3D printed wearable oral- 
drug delivery device in the form of a mouthguard, designed to have tunable drug release rates [108]. University College London (UCL) in partnership with FabRx, a company focussing on using 3D printing for personalised medicines and devices, have also recently performed a world first clinical study whereby a 3D printer was integrated into a hospital pharmacy for personalised treatment of children with a rare metabolic disease [109]. Such advancements demonstrate the revolutionary potential of 3D printing however further studies are required in order to progress this technology away from an academic concept towards real-world benefits for patients.

Currently, commercial 3D printers do not abide by Good Manufacturing Practice (GMP) requirements. As such, regulating their use to produce solid oral dosage forms in a clinical setting, e.g. local pharmacy or hospital remains an unmet need. In addition, all aspects of the printing process would require thorough evaluation to confirm that the final dosage forms are uniform. In fact, the use of multiple production sites adds further technical and logistic challenges, wherein it is difficult to ensure that the end-products are of consistent quality, due to the multiple variables affecting the process including different settings, hardware, raw material suppliers and operator training [3]. Thus, this instigates the need for quality control $(\mathrm{QC})$ measurements, such as the use of non-destructive characterisation methods, including process analytical technologies (PAT), such as near-infrared (NIR) spectroscopy $[10,110,111]$, Raman spectroscopy $[76,112,113]$ or colourimetry $[114,115]$, to monitor drug performance and ensure requirements imposed by regulatory bodies are being fulfilled.

\section{Acknowledgements}


The authors thank the Engineering and Physical Sciences Research Council (EPSRC), UK for their financial support (EP/L01646X).

\section{References}

1. NHS. Improving Outcomes through Personalised Medicine 2016 [15 Aug 19]. Available $\quad$ from: $\quad$ https://http://www.england.nhs.uk/wpcontent/uploads/2016/09/improving-outcomes-personalised-medicine.pdf

2. Basit A, Gaisford S. 3D Printing of Pharmaceuticals. Springer International Publishing; 2018. (AAPS Advances in the Pharmaceutical Sciences Series; 31).

3. Trenfield SJ, Awad A, Goyanes A, et al. 3D Printing Pharmaceuticals: Drug Development to Frontline Care. Trends in pharmacological sciences. 2018;39(5):440-451.

4. Barnatt C. 3D Printing: the next industrial revolution. Barnatt C, editor. UK: Barnatt, C.; 2013.

5. Ventola CL. Medical Applications for 3D Printing: Current and Projected Uses. Pharmacy and Therapeutics. 2014;39(10):704-711.

6. Chowdry A. What can 3D printing do? Here are 6 creative examples. 2013. Available from: https://http://www.forbes.com/sites/amitchowdhry/2013/10/08/what-can3d-printing-do-here-are-6-creative-examples/

7. Sahlgren C, Meinander A, Zhang H, et al. Tailored Approaches in Drug Development and Diagnostics: From Molecular Design to Biological Model Systems. Advanced Healthcare Materials. 2017;6(21):1700258. 
8. Muwaffak Z, Goyanes A, Clark V, et al. Patient-specific 3D scanned and 3D printed antimicrobial polycaprolactone wound dressings. International Journal of Pharmaceutics. 2017;527(1):161-170.

9. Boetker J, Water JJ, Aho J, et al. Modifying release characteristics from 3D printed drug-eluting products. European Journal of Pharmaceutical Sciences. 2016;90:4752.

10. Trenfield SJ, Goyanes A, Telford R, et al. 3D printed drug products: Nondestructive dose verification using a rapid point-and-shoot approach. International Journal of Pharmaceutics. 2018;549(1):283-292.

11. Khaled SA, Alexander MR, Wildman RD, et al. 3D extrusion printing of high drug loading immediate release paracetamol tablets. International Journal of Pharmaceutics. 2018;538(1):223-230.

12. Genina N, Boetker JP, Colombo S, et al. Anti-tuberculosis drug combination for controlled oral delivery using 3D printed compartmental dosage forms: From drug product design to in vivo testing. Journal of Controlled Release. 2017;268:40-48.

13. Awad A, Trenfield SJ, Gaisford S, et al. 3D printed medicines: A new branch of digital healthcare. International Journal of Pharmaceutics. 2018;548(1):586-596.

14. Vuddanda PR, Alomari M, Dodoo CC, et al. Personalisation of warfarin therapy using thermal ink-jet printing. European Journal of Pharmaceutical Sciences. $2018 ; 117: 80-87$.

15. Awad A, Trenfield SJ, Goyanes A, et al. Reshaping drug development using 3D printing. Drug Discovery Today. 2018;23(8):1547-1555. 
16. Fina F, Goyanes A, Madla CM, et al. 3D printing of drug-loaded gyroid lattices using selective laser sintering. International Journal of Pharmaceutics. 2018;547(1):44-52.

17. Goyanes A, Scarpa M, Kamlow M, et al. Patient acceptability of 3D printed medicines. International Journal of Pharmaceutics. 2017;530(1):71-78.

18. Rosenzweig DH, Carelli E, Steffen T, et al. 3D-Printed ABS and PLA Scaffolds for Cartilage and Nucleus Pulposus Tissue Regeneration. International journal of molecular sciences. 2015;16(7):15118-15135.

19. Zhang W, Lian Q, Li D, et al. Cartilage repair and subchondral bone migration using 3D printing osteochondral composites: a one-year-period study in rabbit trochlea. Biomed Res Int. 2014:746138-746138.

20. Castro NJ, O'Brien J, Zhang LG. Integrating biologically inspired nanomaterials and table-top stereolithography for 3D printed biomimetic osteochondral scaffolds. Nanoscale. 2015;7(33):14010-14022.

21. Russmueller G, Liska R, Stampfl J, et al. 3D Printable Biophotopolymers for in Vivo Bone Regeneration. Materials. 2015;8(6):3685-3700.

22. Kim SS, Utsunomiya H, Koski JA, et al. Survival and function of hepatocytes on a novel three-dimensional synthetic biodegradable polymer scaffold with an intrinsic network of channels. Ann Surg. 1998;228(1):8-13.

23. Inzana JA, Olvera D, Fuller SM, et al. 3D printing of composite calcium phosphate and collagen scaffolds for bone regeneration. Biomaterials. 2014;35(13):40264034. 
24. Zhu W, Xu C, Ma B-P, et al. Three-dimensional Printed Scaffolds with Gelatin and Platelets Enhance In vitro Preosteoblast Growth Behavior and the Sustained-release Effect of Growth Factors. Chinese Medical Journal. 2016;129(21):2576-2581.

25. Tsai K-Y, Lin H-Y, Chen Y-W, et al. Laser Sintered Magnesium-Calcium Silicate/Poly-e-Caprolactone Scaffold for Bone Tissue Engineering. Materials (Basel, Switzerland). 2017;10(1):65.

26. Huang J-J, Ren J-A, Wang G-F, et al. 3D-printed "fistula stent" designed for management of enterocutaneous fistula: An advanced strategy. World journal of gastroenterology. 2017;23(41):7489-7494.

27. Tappa K, Jammalamadaka U, Ballard DH, et al. Medication eluting devices for the field of OBGYN (MEDOBGYN): 3D printed biodegradable hormone eluting constructs, a proof of concept study. PloS one. 2017;12(8):e0182929-e0182929.

28. Wickström H, Hilgert E, Nyman JO, et al. Inkjet Printing of Drug-Loaded Mesoporous Silica Nanoparticles-A Platform for Drug Development. Molecules. 2017 Nov;22(11).

29. Awad AF, F.; Trenfield, S.J.; Patel, P.; Goyanes, A.; Gaisford, S.; Basit, A.W. 3D Printed Pellets (Miniprintlets): A Novel, Multi-Drug, Controlled Release Platform Technology. Pharmaceutics 2019;11:148.

30. Robles-Martinez P, Xu X, Trenfield SJ, et al. 3D Printing of a Multi-Layered Polypill Containing Six Drugs Using a Novel Stereolithographic Method. Pharmaceutics. 2019;11(6):274. 
31. Shen S, Wang H, Xue Y, et al. Freeform fabrication of tissue-simulating phantom for potential use of surgical planning in conjoined twins separation surgery. Scientific reports. 2017;7(1):11048-11048.

32. Li B, Wei H, Zeng F, et al. Application of A Novel Three-dimensional Printing Genioplasty Template System and Its Clinical Validation: A Control Study. Scientific Reports. 2017;7(1):5431.

33. Hazeveld A, Huddleston Slater JJR, Ren Y. Accuracy and reproducibility of dental replica models reconstructed by different rapid prototyping techniques. American Journal of Orthodontics and Dentofacial Orthopedics. 2014;145(1):108-115.

34. Schmauss D, Schmitz C, Bigdeli AK, et al. Three-Dimensional Printing of Models for Preoperative Planning and Simulation of Transcatheter Valve Replacement. The Annals of Thoracic Surgery. 2012;93(2):e31-e33.

35. Faber J, Berto PM, Quaresma M. Rapid prototyping as a tool for diagnosis and treatment planning for maxillary canine impaction. American Journal of Orthodontics and Dentofacial Orthopedics. 2006;129(4):583-589.

36. Dawood A, Marti Marti B, Sauret-Jackson V, et al. 3D printing in dentistry. British dental journal. 2015 Dec;219(11):521-9.

37. Oberoi G, Nitsch S, Edelmayer M, et al. 3D Printing-Encompassing the Facets of Dentistry. Frontiers in Bioengineering and Biotechnology. 2018;6:172.

38. Tampi T. SMARTECH REPORT: 3D PRINTING IN DENTAL MARKET TO REACH \$3.1 BILLION BY 20202015 [2nd June 2019]. Available from: https://3dprintingindustry.com/news/smartech-report-3d-printing-in-dentalmarket-to-reach-3-1-billion-by-2020-51971/ 
39. Kattadiyil MT, Mursic Z, AlRumaih H, et al. Intraoral scanning of hard and soft tissues for partial removable dental prosthesis fabrication. The Journal of Prosthetic Dentistry. 2014;112(3):444-448.

40. Stratasys. Stratasys Announces Two New Dental Wax Based 3D Printers, CrownWorx and FrameWorx 2019 [2nd June 2019]. Available from: https://3dprint.com/3711/stratasys-crownworx-frameworx/

41. Chen S-G, Yang J, Jia Y-G, et al. TiO2 and PEEK Reinforced 3D Printing PMMA Composite Resin for Dental Denture Base Applications. Nanomaterials. 2019;9(7).

42. Han J, Kim DS, Jang H, et al. Bioprinting of three-dimensional dentin-pulp complex with local differentiation of human dental pulp stem cells. Journal of Tissue Engineering. 2019;10:1-10.

43. Zein NN, Hanouneh IA, Bishop PD, et al. Three-dimensional print of a liver for preoperative planning in living donor liver transplantation. Liver Transplantation. 2013;19(12):1304-1310.

44. Griffith LG, Swartz MA. Capturing complex 3D tissue physiology in vitro. Nature Reviews Molecular Cell Biology. 2006;7(3):211-224.

45. Yamada KM, Cukierman E. Modeling Tissue Morphogenesis and Cancer in 3D. Cell. 2007;130(4):601-610.

46. Ballard DH, Trace AP, Ali S, et al. Clinical Applications of 3D Printing: Primer for Radiologists. Academic Radiology. 2018;25(1):52-65.

47. Mitsouras D, Liacouras P, Imanzadeh A, et al. Medical 3D Printing for the Radiologist. Radiographics. 2015;35(7):1965-1988. 
48. Zopf DA, Hollister SJ, Nelson ME, et al. Bioresorbable Airway Splint Created with a Three-Dimensional Printer. New England Journal of Medicine. 2013;368(21):2043-2045.

49. Tibbits S. 4D Printing: Multi-Material Shape Change. Architectural Design. 2014;84(1):116-121.

50. Yi H-G, Choi Y-J, Kang KS, et al. A 3D-printed local drug delivery patch for pancreatic cancer growth suppression. Journal of Controlled Release. 2016;238:231-241.

51. Stryker. Stryker's Spine Division Receives FDA Clearance for 3D-Printed Tritanium TL Curved Posterior Lumbar Cage 2018 [2nd June 2019]. Available from: https://http://www.stryker.com/us/en/about/news/2018/stryker sspine-division-receives-fda-clearance-for-3d-printed-t.html

52. Tian P, Yang F, Xu Y, et al. Oral disintegrating patient-tailored tablets of warfarin sodium produced by 3D printing. Drug Development and Industrial Pharmacy. 2018;44(12):1918-1923.

53. Clark EA, Alexander MR, Irvine DJ, et al. 3D printing of tablets using inkjet with UV photoinitiation. International Journal of Pharmaceutics. 2017;529(1):523-530.

54. Kollamaram G, Croker DM, Walker GM, et al. Low temperature fused deposition modeling (FDM) 3D printing of thermolabile drugs. International Journal of Pharmaceutics. 2018;545(1):144-152.

55. Isreb A, Baj K, Wojsz M, et al. 3D printed oral theophylline doses with innovative 'radiator-like' design: Impact of polyethylene oxide (PEO) molecular weight. International Journal of Pharmaceutics. 2019;564:98-105. 
56. Maroni A, Melocchi A, Parietti F, et al. 3D printed multi-compartment capsular devices for two-pulse oral drug delivery. Journal of Controlled Release. 2017;268:10-18.

57. Sadia M, Arafat B, Ahmed W, et al. Channelled tablets: An innovative approach to accelerating drug release from 3D printed tablets. Journal of Controlled Release. 2018;269:355-363.

58. Martinez PR, Goyanes A, Basit AW, et al. Influence of Geometry on the Drug Release Profiles of Stereolithographic (SLA) 3D-Printed Tablets. AAPS PharmSciTech. 2018;19(8):3355-61.

59. Li Q, Guan X, Cui M, et al. Preparation and investigation of novel gastro-floating tablets with 3D extrusion-based printing. International Journal of Pharmaceutics. 2018;535(1):325-332.

60. Goyanes A, Buanz ABM, Basit AW, et al. Fused-filament 3D printing (3DP) for fabrication of tablets. International Journal of Pharmaceutics. 2014;476(1):88-92.

61. Chai X, Chai H, Wang X, et al. Fused Deposition Modeling (FDM) 3D Printed Tablets for Intragastric Floating Delivery of Domperidone. Scientific Reports. 2017;7(1):2829.

62. Alhnan MA, Okwuosa TC, Sadia M, et al. Emergence of 3D Printed Dosage Forms: Opportunities and Challenges. Pharm Res. 2016;33(8):1817-32.

63. Yu D-G, Branford-White C, Yang Y-C, et al. A novel fast disintegrating tablet fabricated by three-dimensional printing. Drug Development and Industrial Pharmacy. 2009;35(12):1530-1536. 
64. Fina F, Madla CM, Goyanes A, et al. Fabricating 3D printed orally disintegrating printlets using selective laser sintering. International Journal of Pharmaceutics. 2018;541(1):101-107.

65. Lee K-J, Kang A, Delfino JJ, et al. Evaluation of Critical Formulation Factors in the Development of a Rapidly Dispersing Captopril Oral Dosage Form. Drug Development and Industrial Pharmacy. 2003;29(9):967-979.

66. Prasad LK, Smyth H. 3D Printing technologies for drug delivery: a review. Drug Dev Ind Pharm. 2016;42(7):1019-31.

67. Jamróz W, Kurek M, Łyszczarz E, et al. 3D printed orodispersible films with Aripiprazole. Int J Pharm. 2017;533(2):413-420.

68. Sadia M, Sośnicka A, Arafat B, et al. Adaptation of pharmaceutical excipients to FDM 3D printing for the fabrication of patient-tailored immediate release tablets. International Journal of Pharmaceutics. 2016;513(1-2):659-668.

69. Goyanes A, Allahham N, Trenfield SJ, et al. Direct powder extrusion 3D printing: Fabrication of drug products using a novel single-step process. International Journal of Pharmaceutics. 2019;567:118471.

70. Vithani K, Goyanes A, Jannin V, et al. A Proof of Concept for 3D Printing of Solid Lipid-Based Formulations of Poorly Water-Soluble Drugs to Control Formulation Dispersion Kinetics. Pharmaceutical Research. 2019;36(7):102.

71. Vithani K, Goyanes A, Jannin V, et al. An Overview of 3D Printing Technologies for Soft Materials and Potential Opportunities for Lipid-based Drug Delivery Systems. Pharmaceutical Research. 2018;36(1):4. 
72. Alomari M, Vuddanda PR, Trenfield SJ, et al. Printing T3 and T4 oral drug combinations as a novel strategy for hypothyroidism. International Journal of Pharmaceutics. 2018;549(1):363-369.

73. Sadia M, Isreb A, Abbadi I, et al. From 'fixed dose combinations' to 'a dynamic dose combiner': 3D printed bi-layer antihypertensive tablets. European Journal of Pharmaceutical Sciences. 2018;123:484-494.

74. Khaled SA, Burley JC, Alexander MR, et al. 3D printing of five-in-one dose combination polypill with defined immediate and sustained release profiles. Journal of Controlled Release. 2015;217:308-314.

75. Pereira BC, Isreb A, Forbes RT, et al. 'Temporary Plasticiser': A novel solution to fabricate 3D printed patient-centred cardiovascular 'Polypill' architectures. European Journal of Pharmaceutics and Biopharmaceutics. 2019;135:94-103.

76. Trenfield SJ, Xian Tan H, Awad A, et al. Track-and-Trace: Novel Anti-Counterfeit Measures for 3D Printed Personalised Drug Products using Smart Material Inks. Int J Pharm 2019;567:118443.

77. Gebhardt A, Schmidt F-M, Hötter J-S, et al. Additive Manufacturing by selective laser melting the realizer desktop machine and its application for the dental industry. Physics Procedia. 2010;5:543-9.

78. Novakov T, Jackson MJ, Robinson GM, et al. Laser sintering of metallic medical materials - $\mathrm{a}$ review. The International Journal of Advanced Manufacturing Technology. 2017;93(5):2723-52. 
79. Goyanes A, Det-Amornrat U, Wang J, et al. 3D scanning and 3D printing as innovative technologies for fabricating personalized topical drug delivery systems. Journal of Controlled Release. 2016;234:41-8.

80. Genina N, Holländer J, Jukarainen $\mathrm{H}$, et al. Ethylene vinyl acetate (EVA) as a new drug carrier for 3D printed medical drug delivery devices. European Journal of Pharmaceutical Sciences. 2016;90:53-63.

81. Holländer J, Genina N, Jukarainen H, et al. Three-dimensional printed PCL-based implantable prototypes of medical devices for controlled drug delivery. J Pharm Sci. 2016;105(9):2665-2676.

82. Tappa K, Jammalamadaka U, Weisman JA, et al. 3D Printing Custom Bioactive and Absorbable Surgical Screws, Pins, and Bone Plates for Localized Drug Delivery. J Funct Biomater. 2019;10(2):17.

83. Morrison RJ, Hollister SJ, Niedner MF, et al. Mitigation of tracheobronchomalacia with 3D-printed personalized medical devices in pediatric patients. Science Translational Medicine. 2015;7(285):285ra64.

84. Banks J. Adding Value in Additive Manufacturing : Researchers in the United Kingdom and Europe Look to 3D Printing for Customization. IEEE Pulse. 2013;4(6):22-26.

85. Ballard DH, Jammalamadaka U, Tappa K, et al. 3D printing of surgical hernia meshes impregnated with contrast agents: in vitro proof of concept with imaging characteristics on computed tomography. 3D printing in medicine. 2018;4(1):1313. 
86. Ota H, Chao M, Gao Y, et al. 3d printed "earable" smart devices for real-time detection of core body temperature. ACS sensors. 2017;2(7):990-997.

87. FDA. Emerging Technology Program 2017. Available from: https://http://www.fda.gov/AboutFDA/CentersOffices/OfficeofMedicalProdu ctsandTobacco/CDER/ucm523228.htm

88. FDA. Technical Considerations for Additive Manufactured Devices 2016. Available from: https://http://www.fda.gov/downloads/MedicalDevices/DeviceRegulationan dGuidance/GuidanceDocuments/UCM499809.pdf

89. organdonor.gov. Organ Donation Statistics 2019 [30th May 2019]. Available from: https://www. organdonor.gov/statistics-stories/statistics.html

90. Klein GL, Y. Wang, M. 3D Printing and Neurosurgery - Ready for Prime Time? World Neurosurgery. 2013;80:3-4.

91. Peng W, Datta P, Ayan B, et al. 3D bioprinting for drug discovery and development in pharmaceutics. Acta Biomaterialia. 2017;57:26-46.

92. Cui X, Boland T, D'Lima DD, et al. Thermal inkjet printing in tissue engineering and regenerative medicine. Recent Pat Drug Deliv Formul. 2012;6(2):149-155.

93. Celprogen. Celprogen Introduces 3D Printed Scaffold Human Heart That May Someday Be Utilized in Heart Transplants 2016. Available from: http://www.celprogen.com/news-details.php?nid=52

94. TCTMagazine. Celprogen Inc successfully 3D print functioning pancreas model 2016 [30th May 2019]. Available from: https://www.tctmagazine.com/3d-printingnews/celprogen-successfully-3d-print-functioning-pancreas/ 
95. Schmid F. Testing a soft artificial heart 2017 [30th May 2019]. Available from: https://www.ethz.ch/en/news-and-events/ethnews/news/2017/07/artificial_heart.html

96. Ge Q, Sakhaei AH, Lee H, et al. Multimaterial 4D printing with tailorable shape memory polymers. Scientific reports. 2016;6:31110.

97. Wei H, Zhang Q, Yao Y, et al. Direct-write fabrication of 4D active shape-changing structures based on a shape memory polymer and its nanocomposite. ACS applied materials \& interfaces. 2016;9(1):876-883.

98. Zarek M, Mansour N, Shapira S, et al. 4D printing of shape memory - based personalized endoluminal medical devices. Macromolecular rapid communications. 2017;38(2):1600628.

99. He H, Guan J, Lee JL. An oral delivery device based on self-folding hydrogels. Journal of Controlled Release. 2006 2006/01/10/;110(2):339-346.

100. Malachowski K, Breger J, Kwag HR, et al. Stimuli - responsive theragrippers for chemomechanical controlled release. Angewandte Chemie International Edition. 2014;53(31):8045-8049.

101. Breger JC, Yoon C, Xiao R, et al. Self-folding thermo-magnetically responsive soft microgrippers. ACS applied materials \& interfaces. 2015;7(5):3398-3405.

102. Azam A, Laflin KE, Jamal M, et al. Self-folding micropatterned polymeric containers. Biomedical microdevices. 2011;13(1):51-58.

103. Yoon C, Xiao R, Park J, et al. Functional stimuli responsive hydrogel devices by self-folding. Smart Materials and Structures. 2014;23(9):094008. 
104. Stoychev G, Puretskiy N, Ionov L. Self-folding all-polymer thermoresponsive microcapsules. Soft Matter. 2011;7(7):3277-3279.

105. Li H, Go G, Ko SY, et al. Magnetic actuated pH-responsive hydrogel-based soft micro-robot for targeted drug delivery. Smart Materials and Structures. 2016;25(2):027001.

106. Melocchi A, Inverardi N, Uboldi M, et al. Retentive device for intravesical drug delivery based on water-induced shape memory response of poly(vinyl alcohol): design concept and 4D printing feasibility. International Journal of Pharmaceutics. 2019;559:299-311.

107. FDA. Technical Considerations for Additive Manufactured Medical Devices. In: U.S. Department of Health and Human Services, editor. United States2017.

108. Liang K, Carmone S, Brambilla D, et al. 3D printing of a wearable personalized oral delivery device: A first-in-human study. Science Advances. 2018;4(5):eaat2544.

109. Goyanes A, Madla CM, Umerji A, et al. Automated therapy preparation of isoleucine formulations using 3D printing for the treatment of MSUD: First singlecentre, prospective, crossover study in patients. International Journal of Pharmaceutics. 2019;567:118497.

110. Vakili H, Wickstrom H, Desai D, et al. Application of a handheld NIR spectrometer in prediction of drug content in inkjet printed orodispersible formulations containing prednisolone and levothyroxine. Int J Pharm. 2017;524(1-2):414-423. 
111. Edinger M, Iftimi L-D, Markl D, et al. Quantification of Inkjet-Printed Pharmaceuticals on Porous Substrates Using Raman Spectroscopy and NearInfrared Spectroscopy. AAPS PharmSciTech. 2019;20(5):207.

112. Lee E. Raman spectral imaging on pharmaceutical products. Infrared and Raman Spectroscopic Imaging: Wiley - VCH Verlag GmbH \& Co. KGaA; 2009. p. 377402.

113. Edinger M, Bar-Shalom D, Rantanen J, et al. Visualization and Non-Destructive Quantification of Inkjet-Printed Pharmaceuticals on Different Substrates Using Raman Spectroscopy and Raman Chemical Imaging. Pharmaceutical Research. 2017;34(5):1023-1036.

114. Vakili H, Nyman JO, Genina N, et al. Application of a colorimetric technique in quality control for printed pediatric orodispersible drug delivery systems containing propranolol hydrochloride. International Journal of Pharmaceutics. 2016;511(1):606-618.

115. Wickström H, Nyman JO, Indola M, et al. Colorimetry as Quality Control Tool for Individual Inkjet-Printed Pediatric Formulations. AAPS PharmSciTech. 2017;18(2):293-302. 